\title{
Furusemide Inhibits Glucose Transport in Isolated Rat Adipocytes Via Direct Inactivation of Carrier Proteins
}

David B. Jacobs, Basab K. Mookerjee, and Chan Y. Jung Biophysics Laboratory and Division of Nephrology and Medicine, Veterans Administration Medical Center and State University of New York at Buffalo, New York 14215

bstract. Furosemide inhibits 3-O-methyl-Dglucose equilibrium flux in isolated adipocytes. The inhibition is saturable with an increasing concentration of furosemide and shows a noncompetitive type of kinetics. Both basal and insulin-stimulated fluxes are equally affected by the inhibition. Hydrochlorothiazide and piretanide also inhibit the flux with a similar potency, whereas bumetanide, a more potent diuretic, is much less potent. To understand the molecular basis of this inhibition, effects of furosemide on the glucosesensitive cytochaslasin B binding activities of adipocytes were studied. Furosemide inhibits the glucose-sensitive cytochalasin B binding of both microsomal and plasma membrane preparations. For both preparations, the inhibition is time dependent and only slowly reversible, is saturable with an increasing concentration of furosemide, shows a noncompetitive type of kinetics with apparent $K_{\mathrm{i}}$ (the inhibitor concentration that gives the half-maximum effect) of 3.5 and $0.7 \mathrm{mM}$ after 2 and $18 \mathrm{~h}$ incubation, respectively, and is essentially identical between the basal and insulin-stimulated adipocytes. The inhibition develops with a first-order rate constant of approximately $0.12 / \mathrm{h}$ at $4^{\circ} \mathrm{C}$. These results indicate that furosemide inhibits glucose transport in adipocytes by directly inactivating transport carriers of both plasma membranes and microsomal reserve pool. This inactivation of glucose carrier may play a part in the diureticinduced glucose intolerance frequently observed during diuretic therapy.

\section{Introduction}

Significant glucose intolerance often develops in patients receiving prolonged treatment with diuretic agents, e.g., furose-

\footnotetext{
Address reprint requests to Dr. Jung.

Received for publication 27 March 1984 and in revised form 12 July 1984.
}

The Journal of Clinical Investigation, Inc.

Volume 74, November 1984, 1679-1685 mide, thiazide, etc. (1-3). The exact mechanisms operative in this effect remain unclear and controversial. The postulated mechanisms fall into two broad classes: $(a)$ due to alterations in pancreatic insulin secretion (4), and (b) due to extrapancreatic effects independent of insulin secretion, such as decreased glucose utilization or transport, and/or decreased insulin sensitivity at the peripheral tissue level $(5,6)$.

Alterations in carbohydrate economy conceivably may be due to effects of the diuretic molecule at any of the specific loci that govern such economy. Depletion of total body potassium stores is known to cause glucose intolerance by reducing pancreatic beta cell responsiveness to glucose (7-9). More recently, Helderman et al. (10) performed glucose clamp studies on normal volunteers and concluded that thiazideinduced glucose intolerance is a result of potassium depletion, which reduces insulin output by the above mechanism.

However, there is also a body of experimental and clinical evidence that suggests that mechanisms independent of pancreatic insulin output or potassium balance may contribute to glucose intolerance caused by diuretics, especially of the benzothiadiazine class $(6,11)$. We have previously shown that furosemide inhibits glucose transport directly in human erythrocytes (12). We now extend our observations to an insulinsensitive tissue, e.g., adipocytes, to show that furosemide inhibits basal and insulin-stimulated glucose transport by directly interacting with the glucose carrier molecule. We suggest that this direct inactivation of glucose carrier may contribute significantly in the glucose intolerance observed during diuretic therapy.

\section{Methods}

Materials. Collagenase was purchased from Worthington Biochemical Corp. (Freehold, NJ). 3-O-methyl-D-glucose (3-OMG), ${ }^{1}$ L-glucose, phloretin, furosemide, hydrochlorothiazide, and cytochalasin B were purchased from Sigma Chemical Co. (St. Louis, MO). $\left[{ }^{3} \mathrm{H}\right]$ Cytochalasin B, 3-O-methyl [ $\left.{ }^{3} \mathrm{H}\right]$-D-glucose were obtained from New England Nuclear (Boston, MA). Bovine albumin powder (CRG-7) was obtained from Armour Pharmaceuticals (Kankakee, IL). Piretanide was a generous gift from Mr. Val Wagner, Hoechst Roussel Pharmaceutical (North Somerville, NJ), and Bumetanide, a generous gift of Dr. P. Sorter,

1. Abbreviations used in this paper: 3-OMG, 3-O-methyl-D-glucose. 
Hoffman LaRoche, Inc. (Nutley, NJ). Insulin (porcine crystalline) was from Eli Lilly \& Co. (Indianapolis, IN). All other chemicals were standard commercial products of reagent grade quality.

Isolation of adipocytes. Adipocytes were isolated from the epididymal fat pads of Sprague Dawley (150-200 g) male rats given free access to lab chow. Fat cells were prepared by the method described by Rodebell (13) and modified as follows. Minced fat pads were put in several 25 -ml polyethylene scintillation vials with $15 \mathrm{ml}$ of Krebs-Ringer bicarbonate buffer containing collagenase $(1.5 \mathrm{mg} / \mathrm{ml})$, bovine serum albumin $(40 \mathrm{mg} / \mathrm{ml})$, and D-glucose $(3 \mathrm{mM})$ as described (14). The vials were then gassed briefly $(10-20 \mathrm{~s})$ with a $95 \% \mathrm{O}_{2}: 5 \% \mathrm{CO}_{2}$ mixture, sealed, and incubated with gentle shaking at $37^{\circ} \mathrm{C}$ for $1 \mathrm{~h}$, at the end of which time the suspension was filtered through a nylon mesh to remove all extraneous tissue. The fat cells were then washed four times in a Krebs-Ringer buffer containing bovine serum albumin $(40 \mathrm{mg} /$ $\mathrm{ml}$ ) and D-glucose (3 $\mathrm{mM}$ ) (this buffer is referred to as incubation buffer) by centrifugation ( $900 \mathrm{~g}$ for $1 \mathrm{~min}$, which gives $80-90 \%$ hematocrit).

Preparation of $150,000 \mathrm{~g}$ total particulate fraction. Isolated fat cells were hypotonically lysed by vortexing the cells for $60 \mathrm{~s}$ in a hypotonic buffer containing $\mathrm{MgCl}_{2}(2.5 \mathrm{mM}), \mathrm{CaCl}_{2}(0.1 \mathrm{mM})$, and $\mathrm{KHCO}_{3}(1$ $\mathrm{mM}$ ) adjusted to $\mathrm{pH}$ 7.2. The suspension was then centrifuged (at $1,000 \mathrm{~g}$ for $1 \mathrm{~min}$ ), the resulting supranatant (containing fat cake and unlysed cells) were separated from lysate and the lysates were pooled and stored on ice. This procedure was repeated with subsequent supranatants four times until only predominantly the fat cake remained, which was discarded. The lysates were spun down in a Beckman ultracentrifuge (Beckman Instruments, Inc., Fullerton, CA) at 150,000 $g$ for $60 \mathrm{~min}$ at $5^{\circ} \mathrm{C}$. The $150,000-g$ pellet was then resuspended in the hypotonic buffer referred to above and stored in liquid nitrogen until used.

Preparation of plasma membrane and microsome fractions. Plasma and microsomal membrane fractions were prepared by the differential centrifugation method described by McKeel and Jarett (15) and modified by Cushman and Wardzala (16). Using a medium (medium 1) composed of $10 \mathrm{mM}$ Tris $\mathrm{HCl}, \mathrm{pH} 7.4$, EDTA (1 mM), and sucrose $(0.25 \mathrm{M})$. Where insulin and/or furosemide-treated cells were used furosemide and/or insulin was also added to medium 1 . The suspension was then transferred in 30-ml aliquots to a glass homogenizer (Arthur H. Thomas Co., Philadelphia, PA) with the pestle rotating at 2,000 $\mathrm{rpm}$. During the homogenization the homogenizer was kept in ice. The homogenate was then centrifuged at $16,000 \mathrm{~g}$ for $15 \mathrm{~min}$. The fat cake was discarded. To isolate the microsomal membrane, the 16,000 $g$ supernatant was spun for $90 \mathrm{~min}$ at $200,000 \mathrm{~g}$, and its pellet was resuspended in the hypotonic buffer and stored in liquid nitrogen.

To isolate plasma membranes, the $16,000 \mathrm{~g}$ pellet of homogenized cells was resuspended in medium 1 and centrifuged for $10 \mathrm{~min}$ at $1,000 \mathrm{~g}$. The subsequent pellet was discarded and the supernatant was centrifuged at $17,000 \mathrm{~g}$ for $20 \mathrm{~min}$. The pellet was resuspended in 2 $\mathrm{ml}$ of medium 1 and layered on a $15-\mathrm{ml}$ of medium (medium 11) composed of sucrose $(1.12 \mathrm{M})$, Tris $(20 \mathrm{mM})$, and EDTA $(1 \mathrm{mM}), \mathrm{pH}$ 7.4 , and centrifuged at $110,000 \mathrm{~g}$ for $60 \mathrm{~min}$ following the method of Cushman (17). This procedure gave a single band of plasma membrane that was visible on the upper portion of medium 11. This portion was removed and suspended in 20 times the volume of medium 1 and centrifuged for $20 \mathrm{~min}$ at $17,000 \mathrm{~g}$. The pellet was resuspended in the hypotonic buffer and stored in liquid nitrogen.

Insulin treatment. Immediately following isolation (for cytochalasin B binding studies) or following incubation with 3-OMG (for flux measurements, see below) 12-ml aliquots of adipose cells (40-50\% cytocrit) were distributed in $25-\mathrm{ml}$ polyethylene scintillation vials containing $10 \mathrm{ml}$ of incubation media and enough insulin to achieve final concentrations at either 0 or $7.0 \mathrm{nM}$. When specified, furosemide was also added to this stage. The cells were then incubated for $45 \mathrm{~min}$ at $37^{\circ} \mathrm{C}$ with gentle shaking.

Furosemide treatment. Furosemide stock solutions were prepared in $75 \%$ methanol in water adjusted to $\mathrm{pH} 10.0$ with $\mathrm{NaOH}$. Furosemide treatments were started by adding an appropriate stock solution to the cell or membrane suspension to give a specified final concentration without exceeding methanol content of $1 \%$, and the mixture was incubated for a given time. Controls contained the same amount of methanol at the same $\mathrm{pH}$. For cytochalasin B binding to membrane preparations, the furosemide treatments were done either with intact cells prior to their membrane isolation (pretreatment) or with isolated membranes (posttreatment). For the binding studies, the temperature during furosemide treatment was $37^{\circ} \mathrm{C}$ (for pretreatment) or $4^{\circ} \mathrm{C}$ (posttreatment).

For a prolonged incubation with furosemide, an adipose tissue culture method was used. Under sterile conditions isolated fat pads were gently rinsed, cut in small pieces, and placed in $100 \times 20$-mm tissue culture dishes $(\sim 3 \mathrm{~g} /$ dish) containing Parker's medium 199 following the method of Maloff and Lockwood (18). When used enough furosemide to give a final concentration of $0.1 \mathrm{mM}$ was added to the incubation medium. The dishes were then incubated at $37^{\circ} \mathrm{C}$ for $48 \mathrm{~h}$ under an atmosphere of $95 \% \mathrm{O}_{2} / 5 \% \mathrm{CO}_{2}$ with the media changed after $24 \mathrm{~h}$.

Measurement of 3-OMG flux. Glucose transport was assessed by measuring equilibrium exchange rates of 3-OMG using tritium-labeled 3-OMG as a tracer and a modification of the oil flotation method of Whitesell and Glieman (19). Isolated cells were incubated with a given concentration of 3-OMG in a Krebs-Ringer buffer ( $\sim 10 \%$ cytocrit) for $30 \mathrm{~min}$ at room temperature. The cell suspension was then briefly centrifuged $(30 \mathrm{~s}$ at $500 \mathrm{~g}$ ) to reduce its volume to a $40-50 \%$ cytocrit. Insulin or furosemide when used, and 3-OMG solution (for controls) were added this stage to given final concentrations and hematocrits of $22-27 \%$ (see above). 200- $\mu$ l aliquots of this cell suspension were transferred into centrifuge tubes $(12 \times 75-\mathrm{mm}$ polypropyline), and then, incubated without shaking for $45 \mathrm{~min}$ at $37^{\circ} \mathrm{C}$. The flux measurements were initiated by injecting $10 \mu \mathrm{l}$ of $0.9 \mu \mathrm{Ci}$ of labeled 3-OMG directly into the cell suspension with an automatic pipette and vortexed gently for $3 \mathrm{~s}$. The flux was terminated by the addition of $3.5 \mathrm{ml}$ of ice cold Krebs-Ringer bicarbonate buffer containing 0.3 $\mathrm{mM}$ of phloretin and $0.15 \% \mathrm{vol} / \mathrm{vol}$ of ethanol. $1 \mathrm{ml}$ of ice-cold silicone oil (relative density, 0.99; viscosity, 100 centistokes) was layered on top of the mixture and the tubes were centrifuged immediately for 1 $\mathrm{min}$ at $2,500 \mathrm{~g}$. The packed cells on top were then removed with a pipe cleaner and placed in counting vials with $10 \mathrm{ml}$ of scintillation fluid (Hydrofluor, National Diagnostics, Somerville, NJ) vortexed vigorously and their radioactivities were counted. Extracellular trapped radioactivity was measured by adding phloretin solution to cells before injection of isotopic 3-OMG.

Cytochalasin B binding assays. Cytochalasin B binding assay was carried out by a centrifugation method that was described from our laboratory (20) with some modification. Binding assay mixture contained membrane preparation (40-80 $\mu \mathrm{g}$ protein, as measured by Pierce reagent [21] using the Pierce standard) in the hypotonic buffer described previously, $0.010 \mu \mathrm{Ci}\left[{ }^{3} \mathrm{H}\right]$ cytochalasin $B$ with a given concentration of unlabeled cytochalasin $\mathrm{B}$, and $500 \mathrm{mM} \mathrm{L}$ - or D-glucose, made up to a final volume of $200 \mu \mathrm{l}$. When so specified (posttreatment) furosemide was also added at this stage. The mixtures were incubated in $230 \mu \mathrm{l}$ 
cellulose proprionate centrifuge tubes for $30 \mathrm{~min}$ at $4^{\circ} \mathrm{C}$, then centrifuged at $200,000 \mathrm{~g}$ for $60 \mathrm{~min}$ at $4^{\circ} \mathrm{C}$. After centrifugation, $50 \mu \mathrm{l}$ of supernatant was removed for measurement of the free $\left[{ }^{3} \mathrm{H}\right]$ cytochalasin B. The remaining supernatant was aspirated completely and inner wall of tubes were scrubbed with cotton swabs to remove any residual medium. Pellets in centrifuge tubes were transferred directly to a 5-ml scintillation vial containing $4 \mathrm{ml}$ of scintillation fluid (Hydrofluor) for measurement of bound $\left[{ }^{3} \mathrm{H}\right]$ cytochalasin B. Radioactivities of both pellets (previously solubilized with $2 \%$ sodium dodecyl sulfate for 12 h) and supernatants were counted in a liquid scintillation spectrophotometer (Nuclear Chicago, Mark II, Chicago, IL). Drug treatments did not affect protein recovery in pellets under the condition used.

\section{Results}

Rate of equilibrium exchange of 3-OMG by isolated adipocytes of rat epidydimal pads measured at $37^{\circ} \mathrm{C}$ as a function of the sugar concentration showed a simple, saturation kinetics with a Michaelis constant $\left(K_{\mathrm{m}}\right)$ of 5-7 $\mathrm{mM}$ and $\phi_{\max }$ (the maximal rate) of $\sim 0.27 \mu \mathrm{mol} / \mathrm{s}$ per $\mathrm{ml}$ cell water at $37^{\circ} \mathrm{C}$ (Fig. 1). The same batch of isolated adipocytes that were treated with insulin ( $7 \mathrm{nM}$ ) for $30 \mathrm{~min}$ at $37^{\circ} \mathrm{C}$ prior to the flux measurement (insulin-stimulated state) showed approximately a threefold high $\phi_{\max }$ value compared with basal state without significant change in $K_{\mathrm{m}}$ value (Fig. 1).

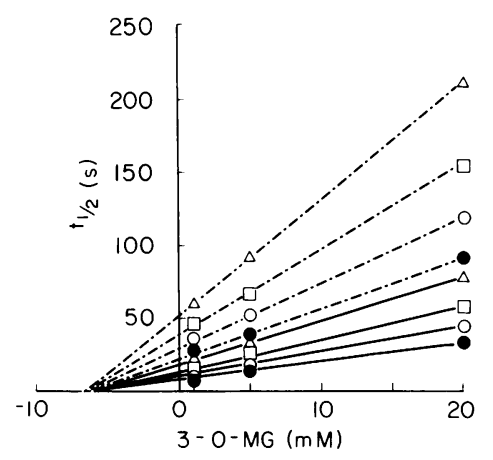

Figure 1. Rates of equilibrium exchange of 3-OMG by isolated adipocytes as a function of 3-OMG concentration. The half-time of equilibration $\left(t_{1 / 2}\right)$ was estimated from the time course of the equilibration analyzed as a first order process. See Figs. 2 and 3 for details. Data are plotted according to a linear transformation of MichaelisMenten equation:

$C / \phi=\left[K_{\mathrm{m}}+C\right] / \phi_{\max }$,

and the relationship (21):

$t_{1 / 2}=0.693 \frac{V_{\mathrm{i}} V_{\mathrm{e}}}{\left(V_{\mathrm{i}}+V_{\mathrm{e}}\right)} \cdot \frac{C}{\phi}$,

where $C, \phi, K_{\mathrm{m}}, \phi_{\max }, V_{\mathrm{i}}$, and $V_{\mathrm{e}}$ denote 3-OMG concentration, flux rate, Michaelis-Menten constant, the maximal flux rate, intracellular water volume, and extracellular water volume, respectively. Furosemide concentrations used are none $(\bullet), 1(0), 3(\square)$, and $6(\Delta)$ $\mathrm{mM}$. Straight lines are drawn by eye to best fit to the data points, obtained from noninsulin-treated cells (broken lines) and insulintreated cells (solid lines).
These isolated adipocytes were incubated with varying concentrations of furosemide for $45 \mathrm{~min}$ at $37^{\circ} \mathrm{C}$ and the effects of this incubation on the equilibrium exchange flux of 3-OMG were studied (Figs. 1, 2, and 3). For each 3-OMG concentration used, furosemide inhibited the flux significantly (Fig. 2). Furosemide treatments also reduced the 3-OMG space of adipocytes significantly and this effect is apparently dosedependent (Fig. 2). This is most likely due to cell shrinkage (23) or cell lysis. Nevertheless, analyses of the flux data using the sugar space observed $\left(S_{\infty}\right)$ for each furosemide concentration shows that the inhibition increases in a simple, saturable manner as the concentration of furosemide in the incubation was increased (Fig. $3 \mathrm{~A}$ ). The furosemide concentration that reduced the flux rate by $50 \%$ (apparent inhibition constant, $K_{\mathrm{i}}$ ) is $\sim 4-5 \mathrm{mM}$ irrespective of the three 3-OMG concentrations used (Fig. $3 \mathrm{~A}$ ). When the same data were plotted as a function of 3-OMG for each furosemide concentration (Fig. 1), it is evident that the inhibition is due to a reduction in $\phi_{\max }$ without any significant change in the $K_{\mathrm{m}}$ value, indicating a noncompetitive mode of inhibition.

The 3-OMG fluxes of insulin-stimulated adipocytes were also inhibited by furosemide (Figs. 1 and $3 \mathrm{~B}$ ). The pattern of

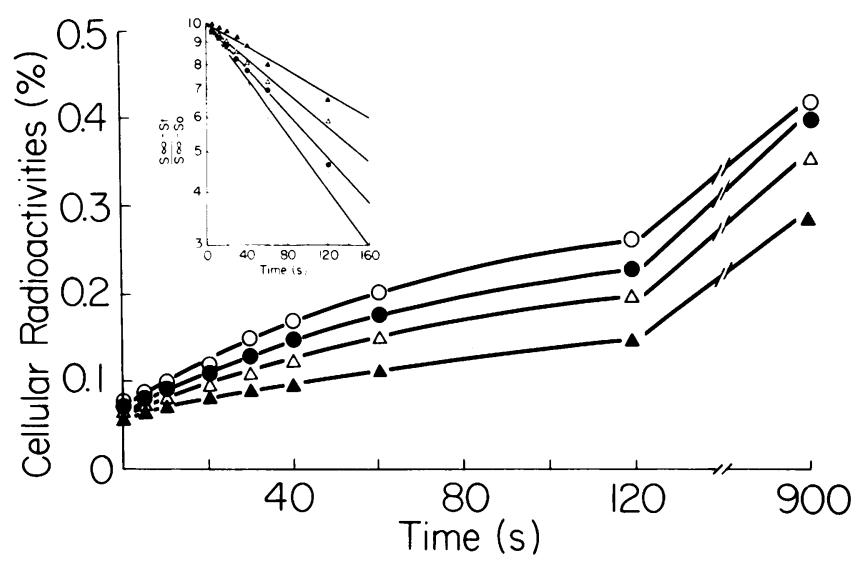

Figure 2. Time course of the equilibrium influx of 3-OMG by isolated adipocytes without $(0)$ and with $1(\bullet), 3(\Delta)$, and $6(\Delta) \mathrm{mM}$ furosemide treatments, respectively. Cells were incubated with 20 mM 3-OMG before the isotopic uptake measurement as described in Methods. Data were analyzed based on a simple model of tracer exchange in a closed system of two compartments in inset according to the equation (22):

$\log \frac{S_{\alpha}-S_{\mathrm{t}}}{S_{\alpha}-S_{0}}=-\frac{1}{2.3} \frac{\left(V_{\mathrm{c}}+V_{\mathrm{c}}\right)}{V_{\mathrm{c}} C_{\mathrm{e}} C} \phi_{\mathrm{t}}$,

where $S_{\mathrm{t}}, S_{\alpha}$, and $S_{0}$ denote cellular radioactivities at a given time, time of complete equilibration ( $15 \mathrm{~min}$ ), time of start of experiment, respectively, and $t$ denotes time. The time course of the tracer equilibrium exchange in this plot fits a reasonably good straight line, from which $t_{1 / 2}$ (the time required for one half of the complete equilibration, in seconds) can be estimated for each 3-OMG concentration. 


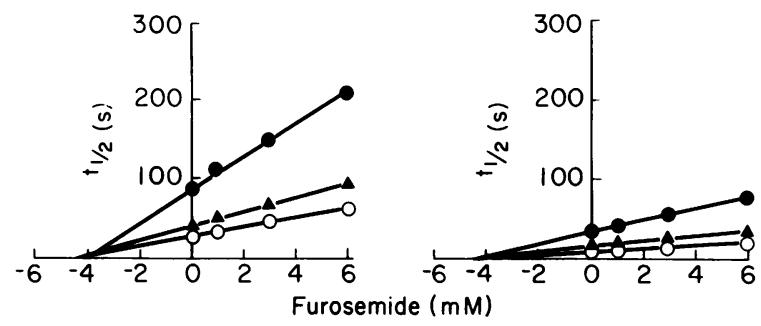

Figure 3. Inhibition of equilibrium exchange of 3-OMG by isolated adipocytes as a function of furosemide concentration. Replot of the data of Fig. 1 according to the equation (24):

$\frac{C}{\phi}=\frac{1}{\phi_{\max }}\left[K_{\mathrm{m}}+C\right]\left[1+\frac{I}{K_{\mathrm{i}}}\right]$,

where $I$ and $K_{\mathrm{i}}$ are inhibitor concentrations and inhibition constants, respectively, and the relationship of $t_{1 / 2}$ to $C / \phi(21)$ as shown in the legend of Fig. 1. The three different concentrations of 3-OMG used were $1(0), 5(\Delta)$, and $20 \mathrm{mM}(\bullet)$ for the basal (left) and insulinstimulated (right) adipocytes.

the inhibition was essentially identical to that of the basal state showing noncompetitive inhibition and an apparent $K_{\mathrm{i}}$ value of $\sim 4.5 \mathrm{mM}$.

Piretanide and hydrochlorothiazide also inhibited 3-OMG equilibrium flux in a similar manner as furosemide, with a $K_{\mathrm{i}}$ value of $\sim 4 \mathrm{mM}$ (data not shown). Bumetanide, however, did not show any significant inhibition at the concentrations up to $3 \mathrm{mM}$ (solubility limit).

Cytochalasin B, a well-established specific inhibitor of glucose transport of adipocytes, binds to purified microsomal and plasma membranes of adipocytes (16, 17). Scatchard analyses of these bindings indicated that there are at least two saturable binding components at the ligand concentration range of up to $10^{-5} \mathrm{M}$. The ligand binding to one of these components is displaced specifically by D-glucose, but not by L-glucose (16). The difference in the ligand bindings observed between these two isomers are taken as the glucose-sensitive binding $(16,20)$.

Effects of furosemide on this glucose-sensitive, cytochalasin $B$ binding to microsomal and plasma membrane preparations were studied by assaying the ligand binding in the presence of $500 \mathrm{mM} \mathrm{L}$ - and D-glucose. In a series of experiments (pretreatment series), cells were first incubated with a given concentration of furosemide prior to their membrane subfractionation. In other experiments (posttreatment series), the membranes were prepared first, then incubated in the presence of furosemide and its effect on the ligand binding was assessed. Both of the furosemide treatments inhibited the cytochalasin B binding of both the microsomal and plasma membranes equally, regardless of whether in basal or in insulin-stimulated states. This is illustrated in Fig. 4 with microsomal membrane preparation of insulin-stimulated adipocytes.

The effects of furosemide on the glucose-sensitive cytochalasin B binding activities of these membrane preparations at both basal and insulin-stimulated states were further analyzed

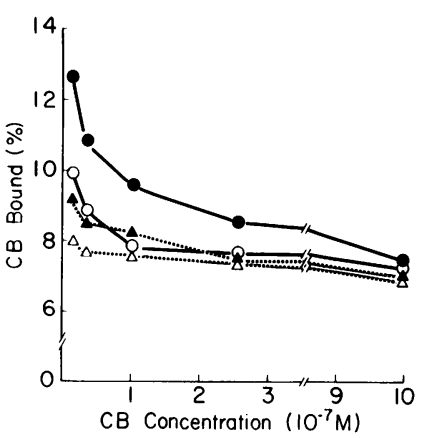

Figure 4. Effect of furosemide on the cytochalasin B binding to a microsomal membrane preparation measured at a varying concentration of cytochalasin B. Isolated adipocytes were incubated with $7 \mathrm{nM}$ insulin in the absence (circles) and presence (triangles) of 6 $\mathrm{mM}$ furosemide (pretreatment) for $30 \mathrm{~min}$ before membrane isolation. The bindings were

assayed in the presence of $500 \mathrm{mM} \mathrm{L}$-(closed symbols) or D-(open symbols) glucose.

by Scatchard plot. In each case, when the incubation time with furosemide is fixed, $B_{\mathrm{T}}$ (total binding capacity) of the glucose-sensitive binding was increasingly reduced as the furosemide concentration was raised in the incubation without affecting affinity (or $K_{\mathrm{D}}$ ) of the binding significantly. This is illustrated in Fig. 5 using plasma membranes prepared from basal state of adipocytes as an example, and the results with all preparations are summarized in Table I. Pretreatment appears slightly more effective than posttreatment throughout all preparations. This may be simply due to the additional exposure to the drug during membrane preparation involved in the pretreatment experiments. Data presented in Table I do not support the contention that furosemide affects insulininduced redistribution of cytochalasin $B$ binding activities between plasma membrane vs. microsomes significantly.

This reduction of the $B_{\mathrm{T}}$ analyzed as a function of furosemide concentration for a fixed incubation time indicates that

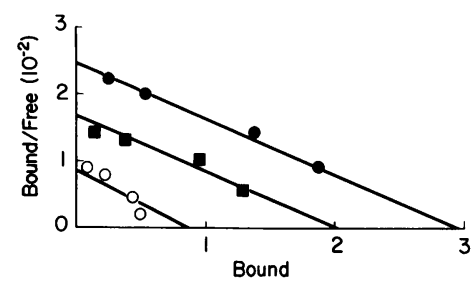

Figure 5. Effects of furosemide on the glucose-sensitive, cytochalasin B binding to a plasma membrane preparation of basal-state adipocytes. The plasma membranes were incubated without $(\bullet)$ and with 1 (ø) or $3(0) \mathrm{mM}$ furosemide for $30 \mathrm{~min}$ at $21^{\circ} \mathrm{C}$. Cytochalasin B binding was measured in the presence of $500 \mathrm{mM}$ L-glucose or D-glucose, each using six different cytochalasin B concentrations $\left(10^{-9}\right.$ to $\left.10^{-5} \mathrm{M}\right)$. The glucose-sensitive cytochalasin $B$ bindings were measured and analyzed by Scatchard plots as stated in the text (16, 19) expressing bound in picomoles per assay tube on the x-axis. The assay mixture contained plasma membranes of protein concentrations 450,360 , and $260 \mu \mathrm{g} / \mathrm{ml}$ for control, $1 \mathrm{mM}$, and $3 \mathrm{mM}$ furosemide experiments, respectively. Each data point represents an average of duplicate determination. Straight lines which were drawn by eye to best fit to data points give the $K_{\mathrm{D}}\left(10^{-7} \mathrm{M}\right)$ and $B_{\mathrm{T}}$ (picomoles per milligram protein) of $1.20,6.6$ for the control; 1.18 , 5.5 for $1 \mathrm{mM}$ furosemide; and $1.05,3.4$, for $3 \mathrm{mM}$ furosemide. 
Table I. Equilibrium Binding Parameters of Glucose-sensitive, Cytochalasin B Binding Component of

Microsomal and Plasma Membrane Preparations

Prior to and After Incubation with $6 \mathrm{mM}$ Furosemide for $2 \mathrm{~h}$

\begin{tabular}{|c|c|c|c|c|c|c|}
\hline \multirow[b]{2}{*}{ Preparations } & \multicolumn{2}{|c|}{ Control } & \multicolumn{2}{|c|}{ Pretreatment } & \multicolumn{2}{|c|}{ Posttreatment } \\
\hline & $B_{\mathrm{T}}$ & $K_{\mathrm{D}}$ & $B_{\mathrm{T}}$ & $K_{\mathrm{D}}$ & $B_{\mathrm{T}}$ & $K_{\mathrm{D}}$ \\
\hline \multirow{3}{*}{$\begin{array}{l}\text { Microsomes, } \\
\text { nonstimulated }\end{array}$} & 35.1 & 1.98 & 5.7 & 1.22 & 9.7 & 1.05 \\
\hline & 35.7 & 1.41 & 7.5 & 1.18 & 11.1 & 1.10 \\
\hline & 48.1 & 1.50 & 5.8 & 1.22 & & \\
\hline \multirow{3}{*}{$\begin{array}{l}\text { Microsomes, } \\
\text { insulin-stimulated }\end{array}$} & 15.3 & 1.20 & 3.6 & 1.05 & 5.2 & 1.05 \\
\hline & 17.0 & 1.41 & 3.3 & 1.20 & 5.3 & 0.95 \\
\hline & 20.8 & 1.22 & 3.2 & 0.95 & & \\
\hline \multirow{2}{*}{$\begin{array}{l}\text { Plasma membranes, } \\
\text { nonstimulated }\end{array}$} & 6.6 & 1.20 & 2.2 & 1.15 & 2.6 & 0.90 \\
\hline & 6.7 & 1.16 & & & & \\
\hline \multirow{2}{*}{$\begin{array}{l}\text { Plasma membranes, } \\
\text { insulin-stimulated }\end{array}$} & & & & & & \\
\hline & 23.5 & 1.26 & 5.4 & 0.96 & 6.5 & 0.98 \\
\hline
\end{tabular}

The furosemide incubation was done either with intact cells (pretreatment) or with membrane preparations (posttreatment). $B_{\mathrm{T}}$ is in picomoles/milligram protein and $K_{\mathrm{D}}$ is in $10^{-7} \mathrm{M}$. Insulin treatment was with $7 \mathrm{nM}$ insulin for $30 \mathrm{~min}$ at $37^{\circ} \mathrm{C}$.

the effect is saturable with a simple stoichiometry (Fig. 6). For a 2-h posttreatment ( $30 \mathrm{~min}$ at room temperature followed by 90 min at $4^{\circ} \mathrm{C}$ ) the $50 \%$ inhibition occurred at the furosemide concentration of $\sim 3.5 \mathrm{mM}$. This apparent $K_{\mathrm{i}}$ value was not significantly different between microsomes and plasma membranes. For an 18-h posttreatment, the concentration that effects $50 \%$ inhibition was reduced to $\sim 0.9 \mathrm{mM}$ for basal microsomes and $0.7 \mathrm{mM}$ for insulin-stimulated microsomes. These findings indicate that the basal and insulin-stimulated states are equally sensitive to the inhibition.

The time dependence of the furosemide effect was already evident in the observed reductions in the apparent $K_{\mathrm{i}}$ value between 2-h and 18-h incubations (Fig. 6). Using a total particulate fraction of adipocytes $(150,000 \mathrm{~g}$ fraction), the time course of the development of the inhibitory effect on the glucose-sensitive cytochalasin B binding was followed for $32 \mathrm{~h}$ (Fig. 7). With the furosemide concentration of $1 \mathrm{mM}$, the inhibition developed as an exponential function of time with a first order rate constant of $\sim 0.12 / \mathrm{h}$ at $4^{\circ} \mathrm{C}$.

In an attempt to examine if the furosemide effect is reversible, a $150,000 \mathrm{~g}$ preparation preincubated with $6 \mathrm{mM}$ furosemide for $3 \mathrm{~h}$ at $4^{\circ} \mathrm{C}$ was, after separation by centrifugation, resuspended into a furosemide-free medium (a final furosemide concentration $<0.06 \mathrm{mM}$ ) for $3 \mathrm{~h}$ at $4^{\circ} \mathrm{C}$. This procedure reduced the inactivation on the glucose-sensitive cytochalasin B binding activity from $71 \%$ down to $25 \%$, indicating that the inactivation is only slowly reversible (data not illustrated).

The effects of longer term incubation with a lower concentration of furosemide on 3-OMG flux was also examined. Adipose pads were incubated for $48 \mathrm{~h}$ at $37^{\circ} \mathrm{C}$ with or without

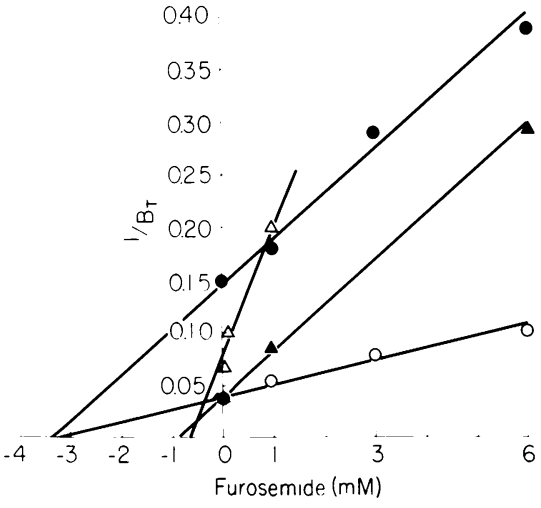

Figure 6. Reduction in $B_{\mathrm{T}}$ of the glucose-sensitive cytochalasin B binding as a function of furosemide concentration $(I)$ according to the relationship $(19,21)$ :

$\frac{1}{B_{\mathrm{T}}}=\frac{1}{B_{\mathrm{T}} \mathrm{O}}\left[1+\frac{I}{K_{\mathrm{i}}}\right]$,

where $B_{\mathrm{T}} \mathrm{O}$ is the $B_{\mathrm{T}}$ obtained without furosemide treatment. Preparations used are the basal state, plasma membranes $(\bullet)$ and basal state microsomes (O) each after 30-min incubation with furosemide, and the basal microsomes $(\Delta)$ and the insulin-stimulated microsomes $(\Delta)$ each after 18-h incubation with furosemide. The glucose-sensitive cytochalasin $B$ binding was quantitated for each preparation using six different cytochalasin B concentrations and the $K_{\mathrm{D}}$ and $B_{\mathrm{T}}$ were calculated as illustrated in Fig. 5 . In each case, $K_{\mathrm{D}}$ value was not changed by the furosemide incubation. Straight lines were drawn by eye to fit to data points. X-intercepts of these lines gave the concentration of furosemide in the incubation that results in the 50\% inhibition (an apparent $K_{\mathrm{i}}$ for that fixed incubation time) of $\sim 3.4$ $\mathrm{mM}$ for the basal state plasma membranes and $3.3 \mathrm{mM}$ for the basal state microsomal membranes both for 30-min incubation. For an 18-h incubation, the apparent $K_{\mathrm{i}}$ values were estimated to be 0.9 and $0.7 \mathrm{mM}$ for the basal state and insulin-stimulated microsomes, respectively.

$0.1 \mathrm{mM}$ furosemide. Adipocytes were isolated from these pads, then treated with insulin (7 $\mathrm{nM})$, and 3-OMG equilibrium flux was measured as described in Methods. The half time $\left(t_{1 / 2}\right)$ observed at the 3-OMG concentration of $5 \mathrm{mM}$ were 22 and $43 \mathrm{~s}$ for control and furosemide-treated samples, respectively. This indicates significant $(50 \%)$ inhibition of transport occurs at therapeutically attainable plasma concentration of furosemide with prolonged incubation of cells at $37^{\circ} \mathrm{C}$. This should be compared with the effect on cytochalasin B binding of an 18 -h incubation at $4^{\circ} \mathrm{C}$ with $0.1 \mathrm{mM}$ furosemide of $\sim 25 \%$ (calculated from data of open triangles in Fig. 6).

\section{Discussion}

We have shown in this study that furosemide inhibits the 3-OMG equilibrium exchange flux in isolated rat adipocytes. The inhibition is independent of insulin since flux in basal as well as insulin-stimulated adipocytes are affected equally. We 


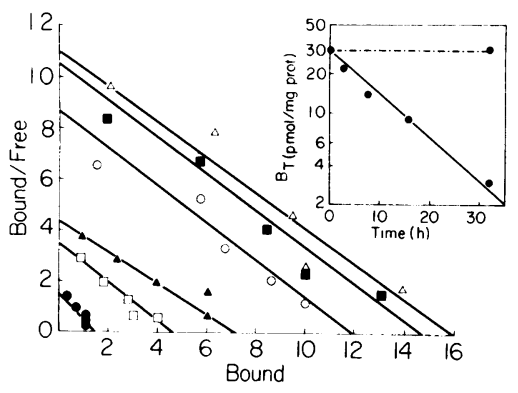

Figure 7. The time course of the development of the furosemide effect on the glucose-sensitive cytochalasin B binding. A total membrane preparation $(150,000 \mathrm{~g}$ particulate fraction) of adipocytes obtained as described in Methods was incubated with $1 \mathrm{mM}$ furosemide for a varying time interval prior to the binding assay. Control without incubation $(\Delta)$; 18-h incubation without furosemide ( $(\Delta)$; and 3-(0), 8-(^), 16-( ( ), and 18-(๑) incubation with furosemide, respectively. The binding data for each preparation were analyzed according to Scatchard with bound/free in $10^{-2}$ and bound in picomoles/ $480 \mu \mathrm{g}$ protein. $B_{\mathrm{T}}$ were calculated from intercepts of horizontal axis of these plots. Inset shows $B_{\mathrm{T}}$ in picomoles per milligram, correlated with incubation time with drug in a semilog plot. Straight lines are drawn by eye.

have also shown that furosemide inhibits the glucose-sensitive cytochalasin B binding activities of both plasma membranes and microsomal membranes of adipocytes. There is ample evidence that glucose-sensitive cytochalasin B binding proteins are the glucose transport carrier molecules in adipocytes and other cells $(16,20,25)$. In adipocytes, these binding proteins exist in two pools, namely in plasma membranes and microsomal membranes, representing active and reserve pools of carrier, respectively $(16,17)$. A widely accepted current hypothesis proposes that insulin induces recruitment of carrier molecules from the microsomal reserve pool into the plasma membrane $(16,17)$, thereby stimulating glucose transport. In the present study we demonstrate that furosemide inhibits the D-glucose-displaceable cytochalasin B binding in both pools with affinities practically indistinguishable from each other. Furthermore, no significant differences were found between the inhibitions observed with samples pretreated with insulin versus noninsulin-treated controls. These data indicate that furosemide inactivates the glucose carrier molecules by direct interaction, and this is independent of their location (plasma membrane vs. microsomes) or of their state (basal- or insulinstimulated). The posttreatment is almost as effective as the pretreatment, indicating that the intact cell structure is not prerequisite to the drug effect. There is no indication in our data that furosemide inhibits insulin-induced recruitment of cytochalasin B binding activity or glucose carriers from microsome to plasma membrane. This is consistent with the observation referred to above that furosemide affects the 3-OMG flux equally independent of insulin treatment.

The carrier inactivation by furosemide appears to be time dependent. The time course of the loss of D-glucose-displaceable cytochalasin B binding activity of total particulate fractions revealed that the inactivation develops slowly. It is a first order process with a rate constant of $\sim 0.12 / \mathrm{h}$ for $1 \mathrm{mM}$ of furosemide at $4^{\circ} \mathrm{C}$. The inactivation is only slowly reversible, being sustained after several washings. When the incubation time with furosemide is fixed, the inhibition observed is a saturable function of inhibitor concentration, which follows noncompetitive mode of inhibition kinetics with one-to-one stoichiometry. The apparent inhibition constant $\left(K_{\mathrm{i}}\right)$ estimated by our analysis was between $3.5-4.5 \mathrm{mM}$ for $2 \mathrm{~h}$ incubation in furosemide. This was the same for both the glucose-flux assay and the cytochalasin B binding assay. When incubation time in furosemide is prolonged to $18 \mathrm{~h}$, the $K_{\mathrm{i}}$ value was reduced to between 0.7 to $0.9 \mathrm{mM}$.

The in vitro inactivation of the glucose carrier by furosemide revealed in this study may have a clinical significance. It should be noted that $K_{\mathrm{i}}$ values for the in vitro effects with a short-term incubation are considerably higher than observed or calculated serum furosemide concentrations in patients receiving therapeutic doses $(<0.1 \mathrm{mM})(12,26,27)$. Nevertheless, in view of the time-dependent, progressive, and poorly reversible nature of the observed effects, even these low blood levels could significantly inhibit glucose transport in peripheral tissues in vivo if drug therapy is continued for extended periods of time. In fact, our preliminary results show that after $48 \mathrm{~h}$ incubation at $37^{\circ} \mathrm{C}$ furosemide at a concentration as low as $0.1 \mathrm{mM}$ inhibits $50 \%$ of transport function. The comparison of effective in vivo vs. in vitro concentrations is complicated by possible enrichment of the drug at specific cellular sites and lack of detailed information on volume of distribution and systemic fate of diuretic agents. Evidence of progressive accumulation of furosemide in renal tissue has been observed $(28$, 29). The loop diuretic ethacrynic acid is also known to be accumulated by kidney slices to concentrations 10 -fold higher than those in the incubation media (30). In other in vitro systems the effective concentrations of furosemide are not markedly different from those causing effects reported in this paper. The concentration of furosemide in perfusion medium that inhibits sodium reabsorption maximally in isolated perfused renal tubule is $1 \mathrm{mM}$ (31). The effective concentration for inhibition of sodium transport in the toad bladder is $0.8 \mathrm{mM}$ (32). Taken together, these considerations suggest that the drug-induced inhibition of glucose transport in peripheral tissues could contribute to the glucose intolerance observed in patients receiving diuretic therapy. Furthermore, our results demonstrate that hydrochlorothiazide and piretinide were as effective as furosemide, while bumetanide was significantly less potent. This is in accordance with reports that bumetanide in equivalent diuretic dosage may be less prone to cause glucose intolerance $(33,34)$.

In conclusion, furosemide and other diuretics inactivate in vitro the glucose transport carrier of adipocyte independent of insulin. We propose that this may contribute to the glucose intolerance in patients receiving diuretic therapy. 


\section{Acknowledgments}

This work was supported by the Veterans Administration Medical Center, Buffalo, NY, and by a grant AM-13376 from the National Institutes of Health.

\section{References}

1. Wilkins, R. W. 1959. New drugs for the treatment of hypertension. Ann. Intern. Med. 50:1-13.

2. Shapiro, A. P., T. G. Benedict, and J. L. Small. 1961. Effect of thiazides on carbohydrate metabolism in patients with hypertension. N. Engl. J. Med. 265:1028-1033.

3. Goldner, M. G., H. Zarowitz, and S. Akgun. 1960. Hyperglycaemia and glycosuria due to thiazide derivatives administered in diabetes mellitus. N. Engl. J. Med. 262:403-405.

4. Fajans, S. S., J. C. Floyd, R. F. Knopf, J. Bull, E. M. Gunsch, and J. W. Conn. 1966. Benzothiadiazine suppression of insulin release from normal and abnormal islet tissue in man. J. Clin. Invest. 41:481493.

5. Weller J. N., and P. E. Borondy. 1965. Effects of benzothiadiazine drugs on carbohydrate metabolism. Metab. Clin. Exp. 14:708-714.

6. Beardwood, D. M., J. S. Alden, C. A. Graham, J. T. Beardwood, and A. Marble. 1965. Evidence for a peripheral action of chlorothiazide in normal man. Metab. Clin. Exp. 14:561-567.

7. Sagild, U., V. Andersen, and P. B. Andreasen. 1961. Glucose tolerance and insulin responsiveness in experimental potassium depletion. Acta Med. Scand. 169:243-251.

8. Rowe, J. W., J. D. Tobin, R. M. Rosa, and R. Andres. 1980. Effects of experimental potassium deficiency on glucose and insulin metabolism. Metab. Clin. Exp. 29:498-502.

9. Gorden, P. 1973. Glucose intolerance with hypokalemia: failure of short term potassium depletion in normal subjects to reproduce the glucose and insulin abnormalities of clinical hypokalemia. Diabetes. 22:544-551.

10. Helderman, J. H., D. Elahi, D. K. Andersen, G. S. Raizes, J. D. Tobin, D. Schocken, and R. Andres. 1983. Prevention of glucose intolerance of thiazide diuretics by maintenance of body potassium. Diabetes. 32:106-111.

11. Barnett, C. A., and J. E. Whitney. 1966. The effect of Diazoxide and chlorothiazide on glucose uptake in vitro. Metab. Clin. Exp. 15:88-93.

12. Jung, C. Y., and B. K. Mookerjee. 1976. Inhibitory effect of furosemide on glucose transport. J. Lab. Clin. Med. 87:960-966.

13. Rodbell, M. 1964. Metabolism of isolated fat cells. I. Effects of hormones on glucose metabolism and lipolysis. J. Biol. Chem. 239:375380.

14. Ciaraldi, T. P., and J. M. Olefsky. 1982. Kinetic relationships between insulin receptor binding and effects on glucose transport in isolated rat adipocytes. Biochemistry. 121:3475-3480.

15. McKeel, D. W., and L. Jarett. 1970. Preparation and characterization of a plasma membrane fraction. J. Cell Biol. 44:417-432.

16. Cushman, S. W., and L. J. Wardzala. 1980. Potential mechanism of insulin action on glucose transport in the isolated rat adipose cell. J. Biol. Chem. 255:4758-4762.

17. Karnieli, E., M. J. Zarnowski, P. J. Hissin, I. A. Simpson, L. B. Salans, and S. W. Cushman. 1981. Insulin stimulated translocation of glucose transport systems in the isolated rat adipose cell. J. Biol. Chem. 256:4772-4777.

18. Maloff, B. L., and D. H. Lockwood. 1981. In vitro effects of a sulfonylurea on insulin action in adipocytes. Potentiation of insulinstimulated hexose transport. J. Clin. Invest. 68:85-90.

19. Whitesell, R. R., and J. Glieman. 1979. Kinetic parameters of transport of 3-O-methylglucose in adipocytes. J. Biol. Chem. 254:52765283.

20. Jung, C. Y., and A. L. Rampal. 1977. Cytochalasin in B binding sites and glucose transport carrier in human erythrocyte ghosts. J. Biol. Chem. 252:5456-5463.

21. Bradford, M. M. 1976. A rapid and sensitive method for the quantitation of microgram quantities of protein utilizing the principle of protein dye binding. Anal. Biochem. 72:248-254.

22. Jung, C. Y., L. M. Carlson, and D. A. Whaley. 1971. Glucose transport carrier activities in extensively washed human red cell ghosts. Biochim. Biophys. Acta. 241:613-617.

23. Geck, P., C. Pietrzyk, B. C. Burckhardt, B. Pfeiffer, and E. Heinz. 1980. Electrically silent cotransport of $\mathrm{Na}^{+}, \mathrm{K}^{+}$and $\mathrm{Cl}^{-}$in Ehrlich cells. Biochim. Biophys. Acta. 600:432-447.

24. Webb, J. L. 1963. Enzyme and Metabolic Inhibitors. Academic Press, New York. 167.

25. Mookerjee, B. K., J. Cuppoletti, A. L. Rampal, and C. Y. Jung. 1981. Effects of cytochalasins on lymphocytes: Identification of distinct cytochalasin binding sites in relation to mitogenic response and glucose transport. J. Biol. Chem. 256:1290-1300.

26. Gutsche, H. U., K. Muller-Ott, R. Brunkhorts, and W. Niedermayer. 1983. Dose related effects of Furosemide, bumetanide and piretanide on the thick ascending limb function in the rat. Can. J. Physiol. Pharmacol. 61:159-165.

27. Deetjen, P. 1966. Micropuncture studies on site and mode of diuretic action of furosemide. Ann. NY Acad. Sci. 139:408-415.

28. Hirsch, G. H., A. P. Pakuts, and A. J. Bayne. 1975. Furosemide accumulation by renal tissue. Biochem. Pharmacol. 24:1943-1946.

29. Cohen, M., E. Hinsch, R. Vergona, J. Ryan, S. J. Kolis, and M. A. Schwartz. 1976. A comparative diuretic and tissue distribution study of bumetamide and furosemide in the dog. J. Pharmacol. Exp. Ther. 197:697-702.

30. Charnock, J. S., H. A. Potter, and D. McKee. 1970. Ethacrynic acid inhibition of $\left(\mathrm{Na}^{+}\right.$and $\left.\mathrm{K}^{+}\right)$-activated ATPase. Biochem. Pharmacol. 19:1637-1641.

31. Lucci, M. S., and D. G. Warnock. 1979. Effects of anion transport inhibitors on $\mathrm{NaCl}$ reabsorption in the rat superficial proximal convoluted tubule. J. Clin. Invest. 64:570-577.

32. Sullivan, L. P., J. M. Tucker, and M. J. Scherbenske. 1971. Effects of Furosemide on sodium transport and metabolism in toad bladder. Am. J. Physiol. 220:1316-1323.

33. Gugliano, D. 1980. Bumetamide and glucose tolerance in man Farm. Ed. Prat. 35:403-408.

34. Kubik, M. M. 1976. Long term experience of the routine use of bumetamide. Br. J. Clin. Prac. 30:11-14. 